\title{
Voltage Generated Characteristics of Piezoelectric Ceramics Cymbal Transducer
}

\author{
Long Wu, Ming-Cheng Chure, King-Kung Wu, Chia-Cheng Tung \\ Department of Electronics Engineering, Far-East University, Tainan City, Chinese Taipei \\ Email: 0602lang@gmail.com
}

Received August 2014

\begin{abstract}
In this study the relation between the generated open circuit output voltages of the piezoelectric ceramics Cymbal transducers with applied impact mechanical energy is studied. The output voltages of piezoelectric ceramics Cymbal transducers are increased with the increasing of the applied mechanical energy. Under the same impact mechanical energy, the generated open circuit output voltages of the piezoelectric ceramics Cymbal transducer is much higher than that of uncapped piezoelectric ceramics disk alone. The generated open circuit output voltages of the piezoelectric ceramics Cymbal transducer depend on the geometry parameters and the metal thickness of end-cap. The generated open circuit voltage of piezoelectric ceramics Cymbal transducer with thick metal thickness is small than that with thin metal thickness.
\end{abstract}

\section{Keywords}

Cymbal Transducer, Piezoelectric, Energy Harvester

\section{Introduction}

After developed by Dogan et al. in 1997 [1], the piezoelectric ceramics Cymbal transducer has been applied in many fields because of the ease of fabrication and the ability to tailor performance, especially to be used as the key element of vibration controller, actuator of microstructure, and hydrophone etc. [2]-[6]. Besides being used as the actuator and sensor, the piezoelectric ceramics Cymbal transducer also can be used as the energy harvester [7]-[12]. Cymbal structure can produce a large in-plane strain under a transverse external force, which is beneficial for the micro energy harvesting. Kim et al. [7]-[10] reported that piezoelectric energy harvesting showed promising results under pre-stress cyclic conditions and validated the experimental results with finite element analysis. The piezoelectric ceramics Cymbal transducer has the ability to generate more electric voltage output and power output as compared to conventional flextensional mode transducer. In the future research, the output electrical characteristic of piezoelectric ceramics Cymbal transducer is generated by mechanical vibrations in a dynamic environment. But in this study, the output electrical characteristic of piezoelectric Cymbal transducer is generated by mechanical vibrations in a static environment study.

\section{Experimental Processes}

The PZT piezoelectric ceramics used in this study were supplied by Eleceram Technology Co., Ltd., Taiwan.

How to cite this paper: Wu, L., Chure, M.-C., Wu, K.-K. and Tung, C.-C. (2014) Voltage Generated Characteristics of Piezoelectric Ceramics Cymbal Transducer. Journal of Materials Science and Chemical Engineering, 2, 32-37.

http://dx.doi.org/10.4236/msce.2014.210005 
The PZT piezoelectric ceramics presented a free dielectric constant $\varepsilon^{\mathrm{T}}{ }_{33}(1 \mathrm{kHz})=2100$, a piezoelectric voltage constant $g_{33}=24 \times 10^{-3} \mathrm{Vm} / \mathrm{N}$, a piezoelectric charge constant $\mathrm{d}_{33}=470 \times 10^{-12} \mathrm{C} / \mathrm{N}$ and $\mathrm{d}_{31}=-230 \times 10^{-12}$ $\mathrm{C} / \mathrm{N}$, a planar electromechanical coupling factor $\mathrm{k}_{\mathrm{p}}=0.70$, a thickness electromechanical coupling factor $\mathrm{k}_{33}=$ 0.72 , a mechanical quality factor $\mathrm{Q}_{\mathrm{m}}=65$.

The structure of piezoelectric ceramics Cymbal transducer was show in Figure 1. The diameter and the thickness of PZT piezoelectric ceramics disk was $15 \mathrm{~mm}$ and $0.9 \mathrm{~mm}$, respectively. The diameter of the end-cap dp was the same as that of the PZT piezoelectric ceramics disk and equal to $15 \mathrm{~mm}$, the cavity depth is keep constant for each sample and equal to $2.0 \mathrm{~mm}$, the dimple diameter de $1=2,3,4$ and $5 \mathrm{~mm}$, and the cavity diameter de $2=5,6,7,8$ and $9 \mathrm{~mm}$. Two types of brass foil were used as end-cap metal of the Cymbal transducer, one with the thickness tb equal to $1.0 \mathrm{~mm}$ (T-series), and the other equal to $0.6 \mathrm{~mm}$ (D-series). There are total 12 types Cymbal transducers with different end-cap parameters were used in this study, 7 for T-series and 5 for D-series, as shown in Table 1.

The electrical output performance of piezoelectric ceramics Cymbal transducer during applying mechanical compressive stress was measured using drop weight impact techniques, in a way as shown in Figure 2. A steel

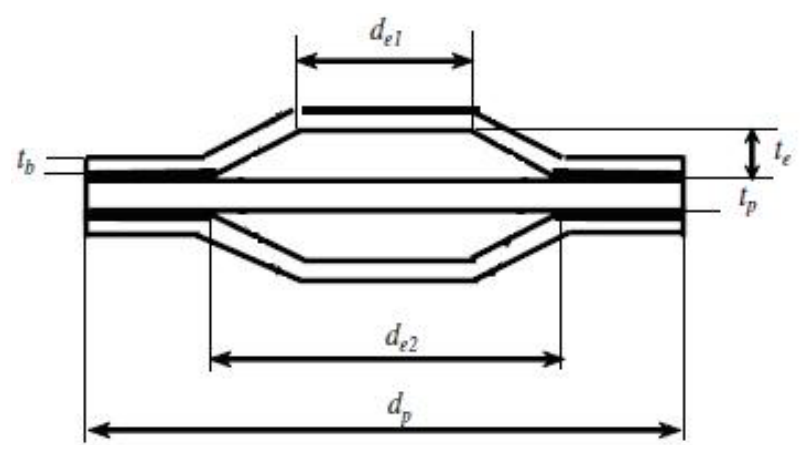

Figure 1. The structure of piezoelectric Cymbal transducer.

Table 1. (a) The end-cap parameters of the T-series Cymbal transducers; (b) The end-cap parameters of the D-series Cymbal transducers.

(a)

\begin{tabular}{cccc}
\hline No. & $\mathrm{d}_{\mathrm{p}}(\mathrm{mm})$ transducer diameter & $\mathrm{d}_{\mathrm{e} 1}(\mathrm{~mm})$ dimple diameter & $\mathrm{d}_{\mathrm{e} 2}(\mathrm{~mm})$ cavity diameter \\
\hline T-1 & 15 & 2 & 9 \\
T-2 & 15 & 3 & 8 \\
T-3 & 15 & 4 & 7 \\
T-4 & 15 & 5 & 6 \\
T-5 & 15 & 2 & 7 \\
T-6 & 15 & 3 & 6 \\
T-7 & 15 & 2 & 5 \\
\hline
\end{tabular}

(b)

\begin{tabular}{cccc}
\hline No. & $\mathrm{d}_{\mathrm{p}}(\mathrm{mm})$ transducer diameter & $\mathrm{d}_{\mathrm{e} 1}(\mathrm{~mm})$ dimple diameter & $\mathrm{d}_{\mathrm{e} 2}(\mathrm{~mm})$ cavity diameter \\
\hline D-1 & 15 & 3 & 8 \\
D-2 & 15 & 4 & 7 \\
D-3 & 15 & 2 & 7 \\
D-4 & 15 & 3 & 6 \\
D-5 & 15 & 2 & 5 \\
\hline
\end{tabular}




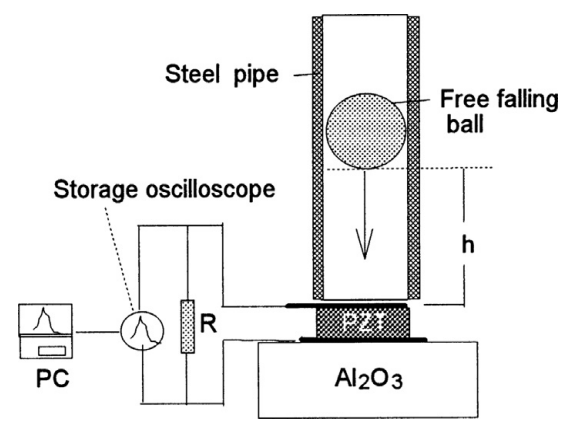

Figure 2. Schematic drawing of the impact testing.

ball (38.6 mm in diameter, $16.5 \mathrm{~g}$ in weight) was dropped from a height from 30 to $120 \mathrm{~mm}$, through a steel guide pipe, there by applying an impact to the test piezoelectric ceramics Cymbal transducer. The electrical response of piezoelectric ceramics Cymbal transducer to applied stress was displayed on a digital storage memory oscilloscope (Agilent MSO-X 3054A) with an input resistance R of $10^{7} \Omega$, which was connected to a personal computer (PC) for data acquisition and analysis.

\section{Results and Discussions}

Figure 3 and Figure 4 have shown the relation between applied mechanical energy and generated open circuit voltage of piezoelectric ceramics Cymbal transducer with the thickness of end-cap metal equal to $1.0 \mathrm{~mm}$ (Tseries) and 0.6mm (D-series), respectively. From the results of Figure 3 and Figure 4, it found that no matter how is the geometry parameter of end-cap, the generated open circuit output voltage of each piezoelectric ceramics Cymbal transducer is increased with the increasing of applied mechanical energy.

In compared with the previous study [13], it found the generated open circuit output voltage of piezoelectric ceramics Cymbal transducer is much larger than that of uncapped piezoelectric ceramic disk alone. From the results of previous study [13], it found when the applied mechanical energy is equal to $45 \mathrm{~mJ}$, the generated open circuit output voltage of uncapped piezoelectric ceramic disk with diameter equal to $15 \mathrm{~mm}$ and thickness equal to $0.9 \mathrm{~mm}$ is about $10 \mathrm{~V}$, but when the same piezoelectric disk used as the piezoelectric element in piezoelectric ceramics Cymbal transducer, the generated open circuit output voltage will increased to about $160 \mathrm{~V}$ to $220 \mathrm{~V}$, dependent on the end cap geometry. The amplification factor of piezoelectric ceramics Cymbal transducer used in this study is equal to 16 to 22, depend on the geometry of the end-cap.

The generated open circuit output voltage of piezoelectric ceramics Cymbal transducer is depend on the geometry of the end-cap structure, and is varies with the ratio of (dimple diameter $d_{e 1} / c a v i t y$ diameter $d_{e 2}$ ). The generated open circuit output voltage of piezoelectric ceramics Cymbal transducer is increased with the increasing of (dimple diameter $d_{e 1} /$ cavity diameter $d_{e 2}$ ) ratio, as shown in Figure $\mathbf{5}$ and Figure 6. In which, Figure $\mathbf{5}$ is the results of T-series piezoelectric ceramics Cymbal transducer, and the Figure 6 is the results of D-series piezoelectric ceramics Cymbal transducer.

Figure 7 shows the relation between generated open circuit voltage and de1/de2 of T-series and D-series piezoelectric ceramics Cymbal transducer with same end-cap structure under different impact mechanical energy. From the results of Figure 7, it found with the same applied mechanical energy and the same end-cap structure, the generated open circuit voltage of piezoelectric ceramics Cymbal transducer with thick metal thickness is small than that with thin metal thickness. The decreased of generated open circuit voltage with the increased of metal thickness is due to the $\mathrm{d}_{\mathrm{eff}}$ decreased with an increase in the end-cap metal thickness [7].

\section{Conclusion}

Open circuit output voltage of piezoelectric ceramic Cymbal transducer increased with the increasing of the applied mechanical energy. Under the same impact mechanical energy, the generated open circuit output voltages of the piezoelectric ceramic Cymbal transducer are much higher than that of uncapped piezoelectric ceramic disk alone. The generated open circuit output voltage of piezoelectric ceramic Cymbal transducer depends on the geometry parameters of the end-cap structure, and is increased with the increasing of (dimple diameter 


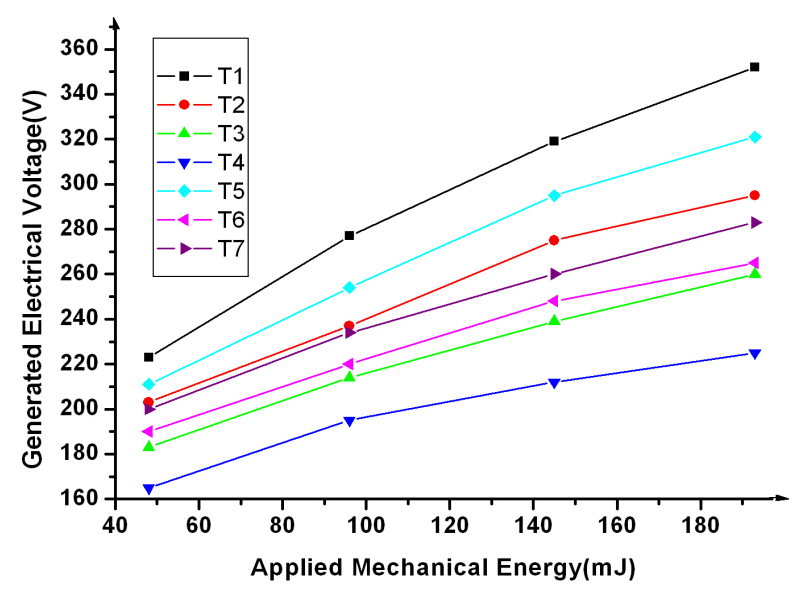

Figure 3. Relation between applied mechanical energy and generated open circuit voltage of T-series piezoelectric ceramics Cymbal transducer.

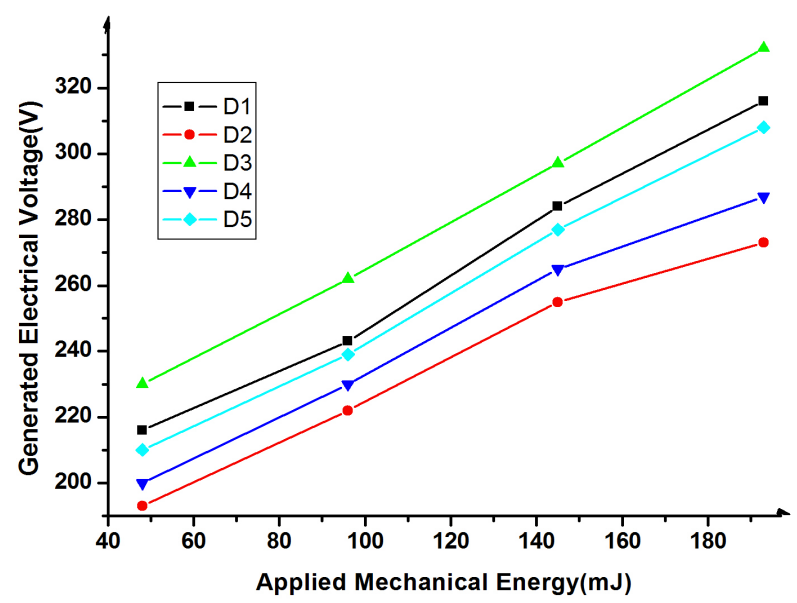

Figure 4. Relation between applied mechanical energy and generated open circuit voltage of D-series piezoelectric ceramics Cymbal transducer.

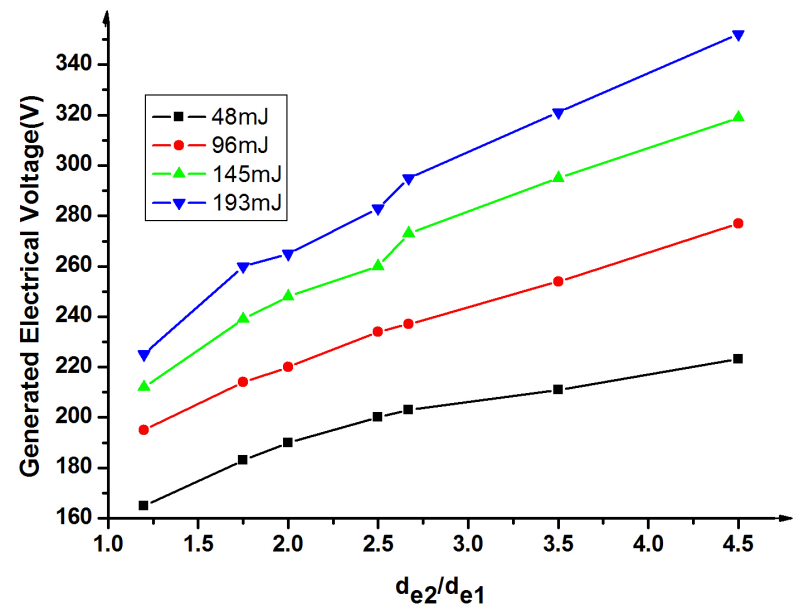

Figure 5. Relation between generated open circuit voltage and $\mathrm{d}_{\mathrm{e} 1} / \mathrm{d}_{\mathrm{e} 2}$ of $\mathrm{T}$-series piezoelectric ceramics Cymbal transducer. 


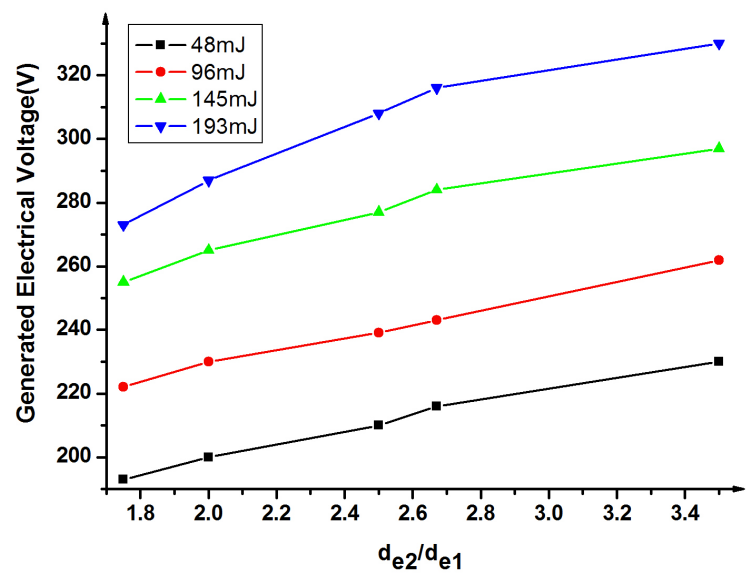

Figure 6. Relation between generated open circuit voltage and $\mathrm{d}_{\mathrm{e} 1} / \mathrm{d}_{\mathrm{e} 2}$ of D-series piezoelectric ceramics Cymbal transducer.

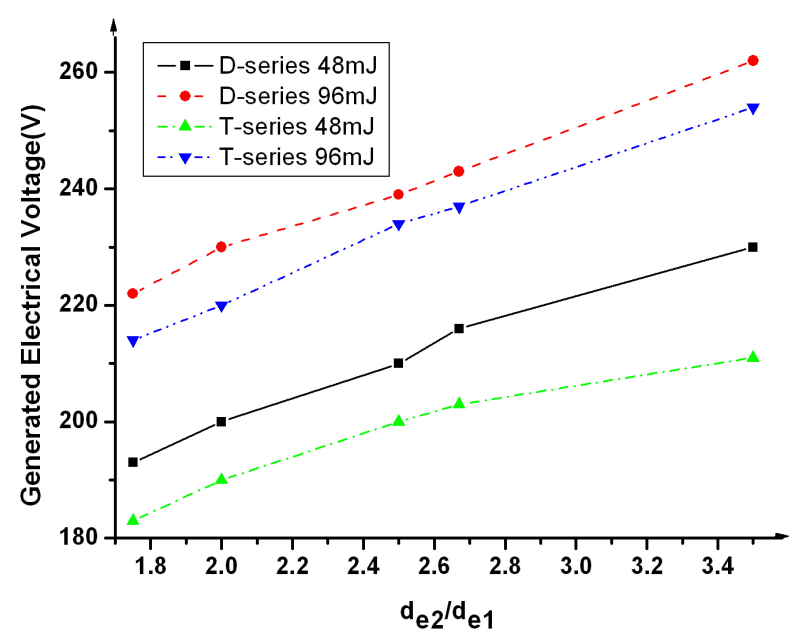

(a)

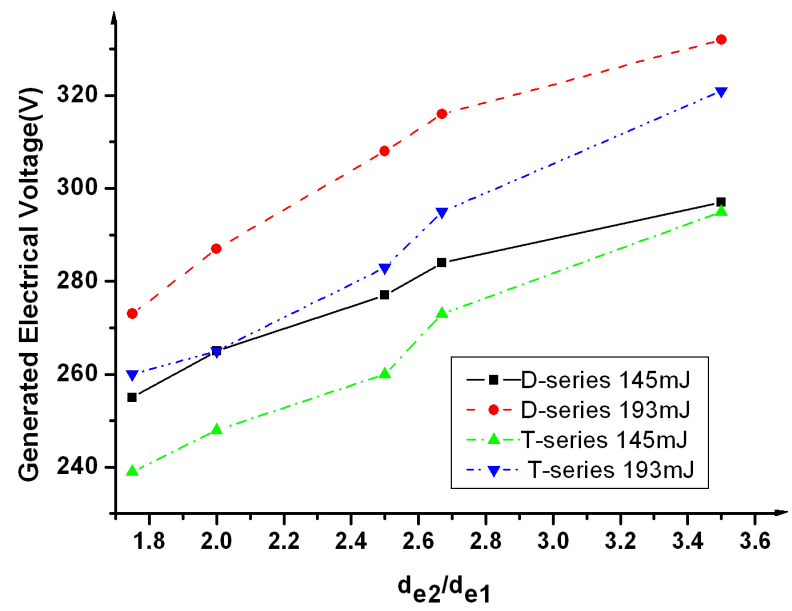

(b)

Figure 7. Relation between generated open circuit voltage and $\mathrm{d}_{\mathrm{e} 1} / \mathrm{d}_{\mathrm{e} 2}$ of T-series and D-series piezoelectric ceramics Cymbal transducer with same end-cap structure under low impact energy. 
$d_{\mathrm{e} 1} /$ cavity diameter $d_{e 2}$ ) ratio. Besides the geometry of the end-cap structure, the generated open circuit output voltages of the piezoelectric ceramic Cymbal transducer also depend on the metal thickness of end-cap, the generated open circuit voltage of piezoelectric ceramic Cymbal transducer with thick metal thickness is smaller than that with thin metal thickness.

\section{References}

[1] Dogan, A., Uchino, K. and Newnham, R.E. (1997) Composite Piezoelectric Transducer with Truncated Conical Endcaps “Cymbal”. IEEE Transactions on Ultrasonics, Ferroelectrics, and Frequency Control, 44, 597-605. http://dx.doi.org/10.1109/58.658312

[2] Meyer Jr., R.J., Dogan, A., Yoon, C., Pilgrim, S.M. and Newnham, R.E. (2001) Displacement Amplification of Electroactive Materials Using the Cymbal Flextensional Transducer. Sens. Actuators A, 87, 157-162.

[3] Meyer Jr., R.J., Hughes, W.J., Montgomery, T.C., Markley, D.C. and Newnham, R.E. (2002) Design of Fabrication Improvements to the Cymbal Transducer Aided by Finite Element Analysis. J. Electroceram., 8, 163-174.

[4] Zhang, J., Hladky-Hennion, A.-C., Hughes, W.J. and Newnham, R.E. (2001) Modeling and Underwater Characterization of Cymbal Transducers and Arrays. IEEE Transactions on Ultrasonics, Ferroelectrics, and Frequency Control, 48, 560-568. http://dx.doi.org/10.1109/58.911739

[5] Li, D.H., Wu, M., Oyang, P.X. and Xu, X.F. (2006) Cymbal Piezoelectric Composite Underwater Acoustic Transducer. Ultrasonics, 44, e685-e687. http://dx.doi.org/10.1016/j.ultras.2006.05.127

[6] Kim, H.W., Batra, A., Priya, S., Uchino, K., Markley, D., Newnham, R.E. and Hofmann, H.F. (2004) Energy Harvesting Using a Piezoelectric “Cymbal” Transducer in Dynamic Environment. Japanese Journal of Applied Physics, 43, 6178-6183. http://dx.doi.org/10.1143/JJAP.43.6178

[7] Kim, H.W., Priya, S., Uchino, K. and Newnham, R.E. (2005) Piezoelectric Energy Harvesting under High Pre-Stressed Cyclic Vibrations. Journal of Electroceramics, 15, 27-34. http://dx.doi.org/10.1007/s10832-005-0897-z

[8] Kim, H.W., Priya, S. and Uchino, K. (2006) Modeling of Piezoelectric Energy Harvesting Using Cymbal Transducers. Japanese Journal of Applied Physics, 45, 5836-5840. http://dx.doi.org/10.1143/JJAP.45.5836

[9] Kim, H.W., Priya, S., Stephanou, H. and Uchino, K. (2007) Consideration of Impedance Matching Techniques for Efficient Piezoelectric Energy Harvesting. IEEE Transactions on Ultrasonics, Ferroelectrics, and Frequency Control, 45, 1851-1859. http://dx.doi.org/10.1109/TUFFC.2007.469

[10] Li, S.Z., Zheng, L., Li, D., Ai, L., Zhang, Z., Guo, S.S. and Zhao, X.Z. (2011) Study of Energy Harvesting Using Piezoelectric Cymbal Transducers. Material Science Forum, 687, 396-401. http://dx.doi.org/10.4028/www.scientific.net/MSF.687.396

[11] Li, X., Guo, M. and Dong, S. (2011) A Flex-Compressive-Mode Piezoelectric Transducer for Mechanical Vibration/ Strain Energy Harvesting. IEEE Transactions on Ultrasonics, Ferroelectrics, and Frequency Control, 58, 698-703. http://dx.doi.org/10.1109/TUFFC.2011.1862

[12] Palosaari, J., Leinonen, M., Hannu, J., Juati, J. and Jantunen, H. (2012) Energy Harvesting with A Cymbal Type Piezoelectric Transducer from Low Frequency Compression. Journal of Electroceramics, 28, 214-219. http://dx.doi.org/10.1007/s10832-012-9713-8

[13] Chure, M.C., Wu, L., Wu, K.K., Tung, C.C., Lin, J.S. and Ma, W.C. (2014) Power Generation Characteristics of PZT Piezoelectric Ceramics Using Drop Weight Impact Techniques: Effect of Dimensional Size. Ceramics International, 40, 341-345. http://dx.doi.org/10.1016/j.ceramint.2013.06.007 